\title{
Diagnosis of Tendinites in Sport Horses
}

Vladimir Konoplev, Mariia Elizarkova, Aleksandr Bokarev, and Sergey Kovalev

Saint-Petersburg State Academy of Veterinary Medicine, St. Petersburg, Russia

\section{Abstract}

Sports horses during training and sporting events get injured to both the thoracic and pelvic limbs in the area of the metacarpus and metatarsus. In this regard, for the differential diagnosis of defeat tendon and ligament and other defeats of the limbs, biochemical blood parameters have been explored related to inflammation markers by visual studies in addition to clinical assessment of the intensity of inflammatory processes. Inflammatory processes in the animal's body are judged by the results of aspirin test, by the level of molecules of average weight, sialic acids, circulating immune complexes. The research revealed changes in the blood of sick horses relatively to healthy ones. Some indicators of markers of inflammation were different: so indicators of aspirin test in the blood of sick animals it was at the level of -- $0.028 \pm 0.002 \mathrm{c}$.u. in the blood of healthy animals it was $-0.015 \pm 0.002$ c.u.; molecules of average weight in diseased animals were level -- $0.216 \pm 0.009$ c.u. and in healthy animals, this indicator was significantly lower and were $0.134 \pm 0.004$ c.u.; index of sialic acid in the blood of sick animals was at the level of -- $2.136 \pm 0.059 \mathrm{mmol} / \mathrm{l}$, and in healthy horses -$0.419 \pm 0.027 \mathrm{mmol} / \mathrm{l}$; circulating immune complexes in the concentration of PEG -$4.14 \%$ in sick horses were $-0.097 \pm 0.009$ c.u. and in healthy -- $0.149 \pm 0.011$ c.u., at PEG $7.25 \%$ in sick animals reached -- $0.343 \pm 0.015$ c.u. and -- 0,174 $\pm 0,011$ c.u. in healthy horses; the content of lysozyme in the blood of sick horses was $145.71 \pm 3.98 \mathrm{mg} / \mathrm{l}$, and in healthy animals -- $143.57 \pm 3.97 \mathrm{mg} / \mathrm{l}$. These studies suggest that changes in these indicators associated with the pathology of tendon-ligamentous apparatus of the limbs of sport horses.

Keywords: horses, markers of inflammation, blood biochemistry.

\section{Introduction}

Selection and Peer-review under the responsibility of the AgroSMART 2019 Conference Committee.

\section{S OPEN ACCESS}

The diseases of the limbs in horses primarily affects tendons located in the distal parts of the limbs below the carpal joint and hock joint. On the rear edge of the metacarpal bone (on the thoracic limbs) and metatarsals (on the pelvic limb) pass the following tendons: 1. interosseous muscle is the suspension ligament. This is a very strong tendon that lies between slate bones; 2 . deep finger flexor -- lies behind the interosseous muscle below attaches to the coffin bone; 3. surface finger flexor -- lies behind a deep finger flexor and has two synovial sheaths, in common with the deep flexor of the finger. The tendon is held on sesamoid bones in the field of the fetlock; 4. common finger extensor 
muscle (on the thoracic limbs) and the long extensor of finger(on pelvic limbs) lie in front of metacarpal and metatarsal bones [2].

A dynamic thermographic study, in the study of different types of pathologies of animal limbs, was used to assess peripheral circulation disorders in the studied part of the body. The method of infrared thermography makes it possible to identify a defect in the early stages of the pathological process before the onset of symptoms. The recorded changes allow preventing and prescribing treatment in time, avoiding complications. Infrared thermography in the practice of a veterinarian can simplify and facilitate the work and reduce stress of animals during their examination $[4 ; 6 ; 14 ; 15]$

The diseases of the limbs of sport horses often associated with defeat the surface and deep flexors of the fingers. Sports horses during training and sporting events get injured to both the thoracic and pelvic limbs in the area of the metacarpus and metatarsus. $X$ ray diagnosis of the limbs of sick animals allows recording clinical signs of tendonitis $[9 ; 12]$. In this regard, for the differential diagnosis of defeat tendon and ligament and other defeats of the limbs, biochemical blood parameters have been explored related to inflammation markers by visual studies in addition to clinical assessment of the intensity of inflammatory processes. These include aspirin test, the molecules of average weight, sialic acid, circulating immune complexes etc. [1, 3, 5, 7--11].

The purpose of this study was to identify some of the markers of inflammation: aspirin test, the molecules of average weight, sialic acids, circulating immune complexes, lysozyme in blood sports horses.

\section{Materials and Methods}

The material for the study was the blood from sports horses from the equestrian club of Leningrad area. Two groups were formed for the study (the first experimental group -- sick animals $n=10$, the second experimental group healthy horses $n=10$ ). The animals were examined according to the generally accepted methodology; local temperature was measured using a portable infrared thermograph HT-02 2.4. Obtained blood samples from test subjects animals were studied in the biochemical laboratory of St. Petersburg SAU. In blood types the following components were determined: molecules of average weight, sialic acids, circulating immune complexes, the concentration of lysozyme and aspirin test by conventional methods. 


\section{Research Result}

During a routine clinical examination of horses, animals with tendon damage in the distal extremities were identified. The pathology was manifested by lameness on a diseased limb, swelling and tenderness of the tendons on the affected part of the limb. When measuring the local temperature on the affected limb, an increase in temperature was detected, this averaged $28.58 \pm 0.09^{\circ} \mathrm{C}$. While in healthy animals, the local temperature of the plantar and carpal limbs was in the range of $20.57 \pm 0.15{ }^{\circ} \mathrm{C}$. The thermography results obtained during the study are reflected in the figures.

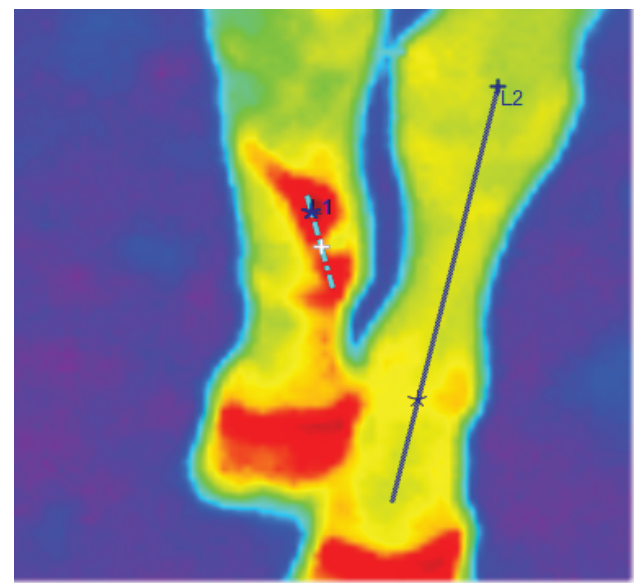

A

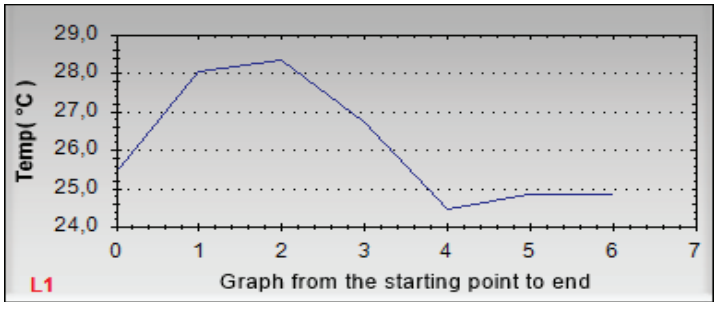

B

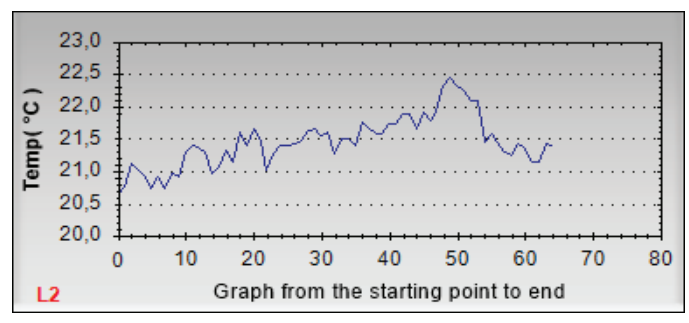

C

Figure 1: A -- Thermogram of the metatarsal region with tendon damage, 5 -- Thermogram of a sick limb, C -- Temperature graph of a healthy limb.

From the data on the given thermograms it can be seen that the temperature difference on the healthy limb in the tendon area on the metatarsal surface was 2 ${ }^{\circ} \mathrm{C}$, from $20.5{ }^{\circ} \mathrm{C}$ for the fetlock joint and $22.5{ }^{\circ} \mathrm{C}$ for the hock joint. The temperature change on the extremities with the affected tendon was $4{ }^{\circ} \mathrm{C}$, varying from $24.5{ }^{\circ} \mathrm{C}$ on the periphery of the focus to $28.5^{\circ} \mathrm{C}$ at the epicenter of the lesion. Thermography data revealed the prevalence of the pathological process on the affected limb in the early stages of the inflammatory process, which allowed the appointment of appropriate therapy to eliminate the identified lesions. 
In order to confirm the revealed lesions of the limbs, a biochemical study of the blood of animals in the experiment was carried out; the data obtained are presented in the table.

TABLE 1: Indicators of inflammation markers in sports horses $(M \pm m)$.

Molecules of average weight mole/l
Sialic acids
Circulating immune complexes PEG-4.14
Circulating immune complexes PEG- 7.25
Lysozymemg/l
Aspirin test

$\begin{gathered}\text { Healthy animals } \\ \mathrm{n}-10\end{gathered}$
$0.134 \pm 0.004$
$0.419 \pm 0.027$
$0.097 \pm 0.009$
$0.174 \pm 0.011$
$134.57 \pm 3.97$
$0.015 \pm 0.002$

\begin{tabular}{c}
$\begin{array}{c}M \pm m \text { Sick animals } \\
n-10\end{array}$ \\
$0.216 \pm 0.009$ \\
$2.136 \pm 0.059$ \\
$0.149 \pm 0.011$ \\
$0.343 \pm 0.015$ \\
\hline $145.71 \pm 3.98$ \\
\hline $0.028 \pm 0.002$
\end{tabular}

$\pi \mathrm{a}$
$<0.001$
$<0.001$
$<0.01$
$<0.001$
$>0.05$
$<0.01$

The studies revealed changes in the blood of sick horses relatively to healthy ones. Some indicators of markers of inflammation were different: so indicators of aspirin test in the blood of sick animals it was at the level of -- $0.028 \pm 0.002 \mathrm{c}$.u. in the blood of healthy animals it was -- $0.015 \pm 0.002$ c.u.; molecules of average weight in diseased animals were level -- $0.216 \pm 0.009$ c.u. and in healthy animals, this indicator was significantly lower and were $0.134 \pm 0.004$ c.u.; index of sialic acid in the blood of sick animals was at the level of -- $2.136 \pm 0.059 \mathrm{mmol} / \mathrm{l}$, and in healthy horses -- $0.419 \pm 0,027 \mathrm{mmol} / \mathrm{l}$; circulating immune complexes in the concentration of PEG -- $4.14 \%$ in sick horses were -- $0.097 \pm 0.009$ c.u. and in healthy -- 0.149 \pm 0.011 c.u., at PEG $7.25 \%$ in sick animals reached -- $0.343 \pm 0,015$ c.u. and $-0.174 \pm 0.011$ c.u. in healthy horses; the content of lysozyme in the blood of sick horses was $145.71 \pm 3.98 \mathrm{mg} / \mathrm{l}$, and in healthy animals -- $143.57 \pm 3.97 \mathrm{mg} / \mathrm{l}$. This studies suggest that changes in these indicators associated with the pathology of tendon-ligamentous apparatus of the limbs of sports horses, which is confirmed by the clinical studies which included examination and palpation of the affected limbs, thermography, during which the swelling of the tendons in the metacarpal region, fluctuation and increase in local temperature, an average of $8.15^{\circ} \mathrm{C}$, which averaged $28.58 \pm 0.34^{\circ} \mathrm{C}$, were also observed, and the animal was lame in the patient limb. The results obtained in the course of the study indicate that significant changes in the concentration of the studied parameters in the blood of sick sport horses which had characteristic changes on compared to healthy animals. Statistical error indicators $(\mathrm{m})$ suggest that the statistical differences presented they were reliable both in the experimental and in the control group of animals. 


\section{Conclusion}

Thus, the obtained results indicate that for the diagnosis of lesions of the tendonligamentous apparatus on the metatarsus and wrist of the limbs of sports horses, it is necessary to approach in a comprehensive manner. Along with the clinical signs of inflammation: swelling, soreness and lameness, it is necessary to determine the local temperature using a portable thermograph on the affected surface of the limbs. This method allows the early detection of damage to the limbs and thereby avoids further moisturizing. A biochemical blood test is also important, namely the determination of markers of inflammation. Clinical significance is given to the indicators of the concentration of molecules of average weight, sialic acids, circulating immune complexes and the results of the aspirin test, which showed significant changes between healthy and sick animals, and indicating the presence of inflammatory processes in the tendonligamentous apparatus of the affected limbs of horses. At the same time, indicators of lysozyme concentration in the blood did not give significant changes indicating a pathological process and, therefore, can not be a reliable marker of inflammation.

\section{References}

[1] Bokarev, A.V. (2014). Diagnosis and treatment of dogs with chronic subdermatit: author's abstract dis Dr. veterinary medicine. St. Petersburg: SAU, p. 47.

[2] Voronin, E.S. (2014). Practicum on clinical diagnosis of with radiology. Moscow, 336 p.

[3] Zelenevskiy, N.V., Sokolov, V.I. (2001). Clinical anatomy of a horse. St. Petersburg, 408 p.

[4] Ilinykh, E.A., Usevich, V.M., Drozd, M.N. (2016). Thermal diagnostics is a promising method of rapid diagnostics in veterinary practice. review of scientific articles. Youth and science, no. 11, p. 13.

[5] Konopatov, Y.V., Vasilyeva, V.S. (2015). Biochemistry of animals. St. Petersburg, 176 p.

[6] Konoplev, V.A., Bokarev, A.V., Kovalev S.P. (2018). The results of a thermographic study of the distal extremities of horses. In the collection: Young knowledge for the development of veterinary medicine and the agricultural sector of the country materials of the international scientific conference of students, graduate students and young scientists, pp. 108--109.

[7] Konoplev, V.A., Bokarev, A.V., Kovalev S.P. (2018). Markers of inflammation in the study of defeat tendon-ligamentous apparatus of the bulls. Materials of national scientific 
and production conference "Science for agricultural production: the relevance and modernity", pp. 46--47.

[8] Kurdeko, A. P. et al. (2018). Methods of diagnosis of diseases of agricultural animals. St. Petersburg, 208 p.

[9] Nikulin, I.A., Kovalev, S.P., Maximov, V.I., Shumilin, Yu.A. (2019). Veterinary radiology. St. Petersburg, 208 p.

[10] Skopichev, V.G. (2010). Molecules of average weight as a criterion for the diagnosis pathological conditions. St. Petersburg: Announcement, p. 30.

[11] Sofronova, N.N. et al. (2015). Specific circulating immune complexes in patients with chronic HCV infection. Practical medicine, no. 92, pp. 100--105.

[12] Stekolnikov, A.A. et al. (2016). X-ray diagnostics in veterinary medicine. St. Petersburg: Special Lit, $379 \mathrm{p}$.

[13] Yarets, Y.I. (2015). Specific proteins: practical guide for doctors in 2 parts, part II Clinical and diagnostic value of the definition of specific proteins. Gomel, p. 47.

[14] Harper, D.L. (2000). Thermography in veterinary medicine. Inframation, no. 1(4), pp. 1$-6$.

[15] Tunley, B.V., Henson, F.M. (2004). Reliability and repeatability of thermographic examination and the normal thermographic image of the thoracolumbar region in the horse. Equine Vet. Journal, no. 36(4), pp. 306--312. 